\title{
Geographic origin may not influence vine weevil Otiorhynchus sulcatus (Fabricius) susceptibility to the entomopathogenic fungus Metarhizium brunneum (Petch)
}

by Morera-Margarit, P., Karley, A.J., Mitchell, C., Graham, R.I. and Pope, T.W.

Copyright, publisher and additional information: .This is the authors' accepted manuscript. The published version is available via Oxford Academic.

Please refer to any applicable terms of use of the publisher 
1 Geographic origin may not influence vine weevil Otiorhynchus sulcatus

2 (Fabricius) susceptibility to the entomopathogenic fungus Metarhizium

3 brunneum (Petch)

4 Pilar Morera-Margarit ${ }^{1,2}$, Alison J. Karley ${ }^{1}$, Carolyn Mitchell ${ }^{1}$, Robert I. Graham ${ }^{3}$,

5 Tom W. Pope ${ }^{2}$

$6 \quad{ }^{1}$ The James Hutton Institute, Dundee, United Kingdom

$7 \quad{ }^{2}$ Harper Adams University, Newport, United Kingdom

$8 \quad{ }^{3}$ Hartpury University, Gloucester, United Kingdom

$9 \quad$ P. Morera-Margarit: pilar.morera.margarit@gmail.com

10 A. J. Karley: Alison.Karley@ hutton.ac.uk

11 C. Mitchell: Carolyn.Mitchell@hutton.ac.uk

12 R. I. Graham: rob.graham @ hartpury.ac.uk

13 Correspondence author:

14 Name: T. W. Pope

15 Address: Harper Adams University, Newport, United Kingdom

16 Phone: +44 (0) 1952815436

17 Email: tpope@ harper-adams.ac.uk

18 Key words: biocontrol, curculionid, larva, soil-dwelling pest, strawberry, survival

19 regression. 


\section{Abstract}

Otiorhynchus sulcatus, known as the vine weevil, is a polyphagous pest that causes economically important damage to horticultural crops worldwide. The entomopathogenic fungus Metarhizium brunneum is widely used to control this pest. Little research has investigated variation in susceptibility to this pathogen between vine weevil populations at different locations. This study addresses this knowledge gap by comparing survival rates of larvae from adults collected in two UK areas when treated with M. brunneum. Larvae from these locations did not differ in their susceptibility, suggesting that location per se may not affect the efficacy of M. brunneum against vine weevil larvae.

\section{Introduction}

The vine weevil, Otiorhynchus sulcatus (Fabricius) (Coleoptera: Curculionidae), is a curculionid endemic to central Europe, yet its distribution has expanded to most parts of Europe, parts of North America, South America, New Zealand and Japan. The vine weevil is highly polyphagous and so threatens a wide range of horticultural crops around the world, among them economically important soft-fruit crops such as strawberry. In the UK alone, more than 2,000 ha of strawberry crops were affected in 2016 and losses were worth an estimated £14M (Wynn, 2010). In addition, ornamental crops, such as plants within the genera Rhododendron, Photinia, Euonymus and Cyclamen are also subject to damage by this pest.

Adult weevils live above-ground and feed on leaves and flowers causing mainly cosmetic damage, whereas larvae live below-ground and feed on plant roots, stems and bulbs, which reduces plant vigour and may cause plant death. Larvae are usually the greatest concern for growers because of the damage they cause affects plant health, but also because as the larvae feed below-ground infestations are sometimes only noticeable when severe damage to the plant has been caused. Hence, control strategies targeting the vine weevil often primarily focus on this 
life stage.

All vine weevils analysed so far are triploid females which reproduce by thelytokous

47 parthenogenesis. This reproductive strategy is expected to be detrimental for adaptation to new

48 habitats, yet it has not hampered vine weevil range expansion. Little research has focused on the

49 biological distinctiveness of populations of this species, which could be the key to understanding

50 vine weevil adaptation ability. Lundmark (2010) compared genetic sequences of weevils

51 collected from Germany, The Netherlands, the UK and the USA. The study inspected a partial

52 sequence of the cytochrome oxidase III, the elongation factor- $1 \alpha$ gene and a fragment of a non-

53 coding nuclear sequence and reported few nucleotide substitutions within these genetic markers.

54 These results were then extrapolated to the whole genome and it was assumed that, genetically,

55 vine weevil populations are not significantly different. This conclusion, however, was limited by

56 the paucity of genetic information on this insect species. This limitation remains today as there

57 has not been any further attempt to investigate the vine weevil genetic diversity.

To identify population diversity at a microbial level, Morera-Margarit et al. (2019)

59 characterised the bacterial community of vine weevils from various locations. The populations

60 tested harboured very similar bacterial community compositions. However, the application of the

61 newly developed bioinformatic pipeline QIIME2 could reveal greater between population

62 variation in future investigations. Morera-Margarit et al. (2019) used QIIME for the analysis of

63 the vine weevil microbiota. This is an open-source bioinformatics pipeline for performing

64 microbiome analysis from raw DNA sequencing. QIIME uses the Operational Taxonomic Unit

65 or OTU approach. In this method, nucleotide sequences of a given percentage similarity, $97 \%$ in

66 most cases, are clustered together generating what is referred to as an OTU. From the clustered

67 sequences in an OTU, the most abundant is chosen as the representative sequence to identify the 
taxonomy of the OTU. QIIME2, the newest version of the pipeline, includes statistical tools to

69 correct for nucleotide sequencing errors. In this manner, QIIME2 generates unique sequences

70 that are used to taxonomically identify bacteria. QIIME2 allows for a more comprehensive

71 understanding of bacterial communities as it takes into account the biological diversity dismissed

72 in the OTU approach (reviewed by Fricker et al., 2019).

73 Fitness variation between vine weevil populations inhabiting separate locations has to

74 date been unexplored. The aim of the present study was to address this knowledge gap by

75 investigating if vine weevils from geographically separate locations differ in their susceptibility

76 to the fungal pathogen Metarhizium brunneum (Petch) (Hypocreales: Clavicipitaceae). M.

77 brunneum is an entomopathogen widely used as part of integrated pest management strategies

78 targeting the vine weevil, especially the larvae of this insect. Thus, in addition to examining vine

79 weevil between population variation, the aim of this research was to contribute to improved

80 control strategies targeting vine weevil larvae. To conduct our experiments, vine weevil adults

81 were collected from two distant locations within the UK. Population variation in susceptibility to

82 M. brunneum was examined in the offspring larvae of these insects. Mortality was statistically

83 analysed using a mixed effects Cox regression model.

84 Materials and methods

85 Vine weevil adults were collected from strawberry crops at two UK sites separated by

$86524 \mathrm{~km}$ : Stafford, Staffordshire, and Invergowrie, Perth and Kinross (collection site $=$

87 population). These vine weevils were kept in Petri dishes lined with moist paper (Kleenex,

88 Kimberly-Clark professional, Kent, UK) and provided with strawberry leaves (Fragaria $\mathrm{x}$

89 ananasa Duchesne, mixed varieties) in controlled conditions (18 $\left.{ }^{\circ} \mathrm{C}, 16: 8 \mathrm{~h} \mathrm{~L}: \mathrm{D}\right)$. 
Strawberry (Fragaria x ananasa, var. Elsanta) plants used for the experiment were grown

91 in $1 \mathrm{~L}$ pots with a 3:1 mixture of compost (peat-sand-perlite $6 \mathrm{~N}$ : 3P: 1K; Everris Ltd, Ipswich,

92 UK): grit sand (Arthur Bower's Ltd, Lincoln, UK). Vine weevil eggs were collected from Petri

93 dishes in which the collected adults had fed on strawberry leaves for a week. To infest the plants,

9420 eggs were gently washed into a small indentation in the surface of the compost $2 \mathrm{~cm}$ deep and

$951 \mathrm{~cm}$ wide at $2 \mathrm{~cm}$ from the main plant stem. Compost temperature was measured with

96 thermocrons (DS1921G-F5 thermocrons, Homechip Ltd, Milton Keynes, UK), placed 5 cm deep

97 in the compost, and the software OneWireViewer.exe v. 0.3.19.47. Average substrate

98 temperature was $15^{\circ} \mathrm{C} \pm 6^{\circ} \mathrm{C}$. Plants were arranged in a randomised block design, each block

99 comprising two strawberry plants representing a replicate of each population. Three blocks were

100 infested each week for 14 weeks. Experiments were completed in a glasshouse $\left(14-20^{\circ} \mathrm{C}, 16: 8 \mathrm{~h}\right.$

101 L:D).

102 Larvae were collected four to six months after the plants had been infested with eggs by

103 removing the plants from the pots and hand searching the compost and roots for larvae. Only

104 larvae that were between $0.045 \mathrm{~g}$ and $0.09 \mathrm{~g}$ in weight were used in this experiment. Plants from

105 blocks infested during three consecutive weeks were grouped to ensure enough larvae were

106 collected for a single experiment.

107 Metarhizium brunneum isolate 275.86, strain commercialised as Met52® (Novozymes,

108 Denmark), was provided by Warwick Crop Centre at Warwick University, UK. Cultures of this

109 isolate were grown for 14 days in Sabouraud dextrose agar media (20 g glucose, BDH,

110 Lutterworth, UK; 5 g mycological peptone, Oxoid, Basingstoke, UK; 10 g technical agar no.3,

111 Oxoid, Basingstoke, UK; $500 \mathrm{ml}$ deionised water) in the dark at $23^{\circ} \mathrm{C} \pm 1^{\circ} \mathrm{C}$. Conidia were

112 harvested by gentle agitation in sterile $0.01 \%$ Triton X-100 solution (BDH, Lutterworth, UK). 
113 Conidia concentration was enumerated using a Neubauer improved haemacytometer. Conidia

114 were then spun down and re-diluted with sterile water to a final concentration of $10^{7}$ conidia/mL.

115 This conidia suspension was diluted with a Triton X-100 solution to achieve a working

116 concentration of $10^{6}$ conidia/mL in $0.05 \%$ Triton.

117 Vine weevil larvae treatment consisted of pipetting $25 \mu \mathrm{L}$ of conidia suspension onto the

118 thoracic segments close to the head of the larva (Klingen et al., 2015). Negative controls were

119 treated with the same volume of $0.05 \%$ Triton X-100 solution. Galleria mellonella (Linnaeus)

120 (Lepidoptera: Pyralidae) larvae (Big larvae, UK Waxworms Ltd) were used as positive controls

121 and were treated with $25 \mu \mathrm{L}$ of conidia suspension in a similar way. Larvae were placed in Petri

122 dishes (92 mm diameter) with a $1 \mathrm{~cm}$ deep layer of moist compost (insecticide-free peat-sand-

123 perlite $6 \mathrm{~N}$ : $3 \mathrm{P}: 1 \mathrm{~K}$; Everris Ltd, Ipswich, UK) and thin carrot slices as a food source at $18^{\circ} \mathrm{C}$, in

124 the dark (Klingen et al., 2015).

125 Each experimental replicate (4 experimental replicates in total) was arranged as a

126 randomised block design comprising four blocks. Each block contained at least one $M$.

127 brunneum treatment dish per vine weevil population, two negative control dishes for each vine

128 weevil population and one positive control dish consisting of Galleria mellonella treated with $M$.

129 brunneum. Given that natural mortality of vine weevil larvae can be variable, for example as a

130 result of a natural infections or disturbance occasionally killing all weevils within a Petri dish,

131 two negative control dishes were used per population replicate in order to accurately record

132 control mortality in this experiment. The position of the dishes within the block was randomised.

133 Petri dishes with the same treatment, i.e. conidia-treatment or control, within the same

134 experiment replicate always contained the same number of larvae. Petri dishes were assessed

135 once each week in a four-week period by removing and counting dead larvae, and replacing the 
136 carrot slices. Mortality caused by the fungal pathogen was manually assessed by applying a

137 slight pressure to identify mummified larvae, as well as visually by observing white mycelia

138 and/or green conidia on the larval surface. Initial numbers of larvae per population and treatment

139 were: Stafford-control $=28$, Stafford-conidia treatment $=61$, Invergowrie-control $=43$ and

140 Invergowrie-conidia treatment $=154$.

141 Statistical analysis and graphical representation were performed using R software v. 3.3.3

142 and the packages ggplot2 survival (T. M. Therneau \& Grambsch, 2000), coxme (T. C. Therneau,

143 2018), survminer (Kassambara \& Kosinski, 2018), car and plyr. To test for significant

144 differences a survival object was created and was tested using a mixed effect Cox model for

145 interactions. The model included the interactions between the fixed factors vine weevil

146 population-conidia treatment and the random factors block and experiment replicate. A post-hoc

147 log-rank test for multiple comparisons with Benjamini-Hochberg p-value adjustment method was 148 performed.

149 Results

150 The Mixed effects Cox regression to test for the effect of M. brunneum on larval survival 151 revealed a significant effect of the treatment although not for the population of origin $\left(\chi^{2}=10.15\right.$, 152 d.f. $=1$, p-value for treatment $=0.001)$. The Cox proportional hazard, or hazard ratio $(\mathrm{HR})$,

153 calculated for treatment indicated that treating larvae with conidia increased the mortality rate by 154 a factor of $2.2(\mathrm{HR}=2.2)$. The hazard ratio for population also indicated that the origin of the vine 155 weevil population did not affect larvae survival $(\mathrm{HR}=1)$. The post-hoc analysis revealed a 156 significant decrease in survival of conidia-treated larvae over the experimental period within 157 population but no differences were found between the two populations (Stafford control-conidia 158 treatment $\mathrm{p}$-value $=0.003$, Invergowrie control-conidia treatment $\mathrm{p}$-value $=0.003 ;$ Figure 1 ). 
Closer inspection at the descriptive statistics revealed that there was background

160 mortality in the negative control larvae. Mortality was higher for the Invergowrie population,

161 although it showed greater variation for the Stafford population (median values for survival:

162 Stafford-control $=2$ weeks $95 \%$ CI $[2,4]$, Stafford-conidia treatment $=2$ weeks 95\% CI $[2,2]$,

163 Invergowrie-control $=2$ weeks $95 \%$ CI [2, 3], Invergowrie-conidia treatment $=2$ weeks $95 \%$ CI

$164[2,2])$. We attribute this mortality to stress induced during collection and handling of the larvae

165 when setting-up the experiment, as well as due to the artificial experimental conditions.

166 Background mortality did not affect the efficacy of the entomopathogenic fungus under

167 the conditions used for our experiments. In the $1^{\text {st }}$ treatment week, probability of survival was

168 similar between control and conidia-treated larvae (Table 1). After the $1^{\text {st }}$ week, however, the

169 probability of survival in conidia-treated larvae decreased to a much higher level than the

170 probability of survival in the control larvae (Table 1). Additionally, both conidia treatments had

$171100 \%$ mortality at the end of the experiment (Table 1). Hence, despite having background

172 mortality in control larvae throughout the experimental period, a mortality rise in conidia-treated

173 larvae was attributed to the fungal pathogen.

174 The difference in number of larvae from each weevil population used reflects differences

175 in larval mortality during the rearing of these insects on pot grown plants. High mortality when

176 rearing vine weevil larvae on potted plants has been previously reported, with levels of mortality

177 ranging from 80 to $99 \%$. The reason(s) for this high mortality is as yet unknown, although it has

178 been suggested that cannibalism or lack of nutrients could be the underlying cause (LaLone \&

179 Clarke, 1981).

180 Discussion \& Conclusion 
This study is the first to investigate differences in susceptibility of vine weevil larvae

182 collected at different geographic locations to the entomopathogenic fungus M. brunneum. It adds

183 to the limited literature employing survival analysis to examine vine weevil susceptibility to $M$.

184 brunneum (there is only one other study: Klingen et al., (2015)). Our experiments confirm that

185 M. brunneum can infect vine weevil larvae despite using a temperature close to the lower fungal

186 growth threshold following the experiments carried out by Klingen et al. (2015). However, we

187 did not detect differences in susceptibility to M. brunneum associated with vine weevil

188 population.

Mortality values on larvae treated with conidia obtained in our experiments were similar

190 to values reported by Klingen et al., (2015), despite the fact that Klingen et al., (2015) applied a

191 10-fold higher conidia concentration. This may suggest that the conidia concentration used for

192 our experiments saturated the immune response capacity of the insect, which could have masked

193 location-associated variation in susceptibility to this natural enemy. It would therefore be useful

194 to test lower conidia concentrations in future research to reveal the existence of geographic

195 differences in resistance to this entomopathogenic fungus.

196 Vine weevil larvae are known to be subject to high levels of mortality when reared under

197 artificial conditions. Rearing vine weevil larvae on pot grown plants presents a more natural

198 environment but despite this, larval mortality remains high and has previously been reported to

199 be above 80\% under such conditions (LaLone \& Clarke, 1981). Klingen et al., (2015) tested

200 survival of vine weevil larvae following exposure to different entomopathogenic fungi. These

201 experiments were carried out in controlled environment rooms with set temperature, humidity

202 and light regime. However, mortality was still high reaching approximately $50 \%$ for control 
203 larvae after four weeks in these experiments. In our experiments, mortality of larvae not exposed

204 to M. brunneum conidia was similarly high at the end of the experimental period.

205 The application of a Cox regression model to analyse our data allows a more robust

206 analysis of the entomopathogen action irrespective of larval mortality in the control group. This

207 survival analysis determines the probability of survival at each time point and the hazard ratios

208 for each of the variables. Statistical methods for survival analysis are superior to linear

209 regressions to test pesticide susceptibility. This is because survival regressions take into account

210 the time passed until an event occurs (i.e. the speed of entomopathogen action), while linear

211 regressions only take into account the number of individuals that experienced the event by the

212 end of the experimental period (George et al., 2014).

213 This study is limited by the small number of populations tested, yet, it establishes the

214 foundations for future research focusing on testing the existence of niche-associated changes in

215 vine weevil resistance to M. brunneum. Results presented here suggest that location-specific

216 strategies for vine weevil control using M. brunneum may not be necessary. Nonetheless,

217 additional vine weevil populations collected from a wider range of locations but also from a

218 greater diversity of cropped and uncropped habitats should still be studied in this way. These

219 experiments will contribute to confirming whether susceptibility to M. brunneum remains

220 consistent regardless of the geographic origin or crop environment.

221 Metarhizium brunneum is commercialised as a product for which application is currently

222 standardised, hence the same procedure is applied irrespective of the geographic area or the crop

223 affected. This initial study indicates that $M$. brunneum is equally effective regardless of the

224 geographic origin of the vine weevil population, however, additional work is still required to

225 confirm these initial findings. 


\section{Acknowledgments}

227 PMM was funded by the James Hutton Institute and Harper Adams University through a joint 228 PhD studentship. AJK and CM were funded through the strategic research program funded by 229 the Scottish Government's Rural and Environment Science and Analytical Services Division and 230 the research was supported by the Underpinning Capacity project 'Insect Pest Collections'. TP 231 and RB were supported by Harper Adams University. At the James Hutton Institute (Dundee, 232 UK), we thank Dr Jim McNicol (BioSS, Dundee), Dr Katharine Preedy (BioSS, Dundee) and Dr

233 Daniel Leybourne for excellent advice for designing the experiments and analysing the data, and

234 Dr Nikki Jennings and Dr Dorota Jarret for helpful comments on the manuscript. At Warwick

235 University we thank Gill Prince for providing Metarhizium brunneum conidia. We also thank Dr

236 Federica Caradonia, Amanda Tercero Araque, Magdalena Ślachetka and Araceli Torró Galiana

237 for their assistance in collecting vine weevil larvae. We thank Jaume Morera Margarit for 238 contributing with the design of the graphical abstract We also thank the reviewers of this 239 manuscript which have contributed to improve the clarity of our arguments.

\section{$240 \quad$ References}

241 Fricker, A. M., Podlesny, D., \& Fricke, W. F. (2019). What is new and relevant for sequencing-based microbiome research? A mini-review. Journal of Advanced Research, 19, 105-112. https://doi.org/10.1016/j.jare.2019.03.006

244 George, B., Seals, S., \& Aban, I. (2014). Survival analysis and regression models. Journal of Nuclear Cardiology : Official Publication of the American Society of Nuclear Cardiology, 21(4), 686-694. https://doi.org/10.1007/s12350-014-9908-2 
248 Kassambara, A., \& Kosinski, M. (2018). survminer: Drawing survival curves using

“ggplot2.” R Package Version 0.4.3. https://cran.rproject.org/web/packages/survminer/survminer.pdf

251 Klingen, I., Westrum, K., \& Meyling, N. V. (2015). Effect of Norwegian LaLone, R. S., \& Clarke, R. G. (1981). Larval development of Otiorhynchus entomopathogenic fungal isolates against Otiorhynchus sulcatus larvae at low temperatures and persistence in strawberry rhizospheres. Biological Control, 81, 1-7. https://doi.org/10.1016/J.BIOCONTROL.2014.10.006

sulcatus (Coleoptera: Curculionidae) and effects of larval density on larval mortality and injury to rhododendron. Environmental Entomology, 10(2), 190-191. https://doi.org/10.1093/ee/10.2.190

Lundmark, M. (2010). Otiorhynchus sulcatus, an autopolyploid general-purpose genotype species? Hereditas, 147(6), 278-282. https://doi.org/10.1111/j.1601-5223.2010.02198.x

Morera-Margarit, P., Bulgarelli, D., Pope, T. W., Graham, R. I., Mitchell, C., \& Karley, A. J. (2019). The bacterial community associated with adult vine weevil (Otiorhynchus sulcatus) in UK populations growing on strawberry is dominated by Candidatus Nardonella. Entomologia Experimentalis et Applicata, 167(3), 186-196. https://doi.org/10.1111/eea.12757

267 Therneau, T. C. (2018). Mixed effects cox models. $R$ package version 2.2-10; 2018. 
Therneau, T. M., \& Grambsch, P. M. (2000). Modeling Survival Data: Extending

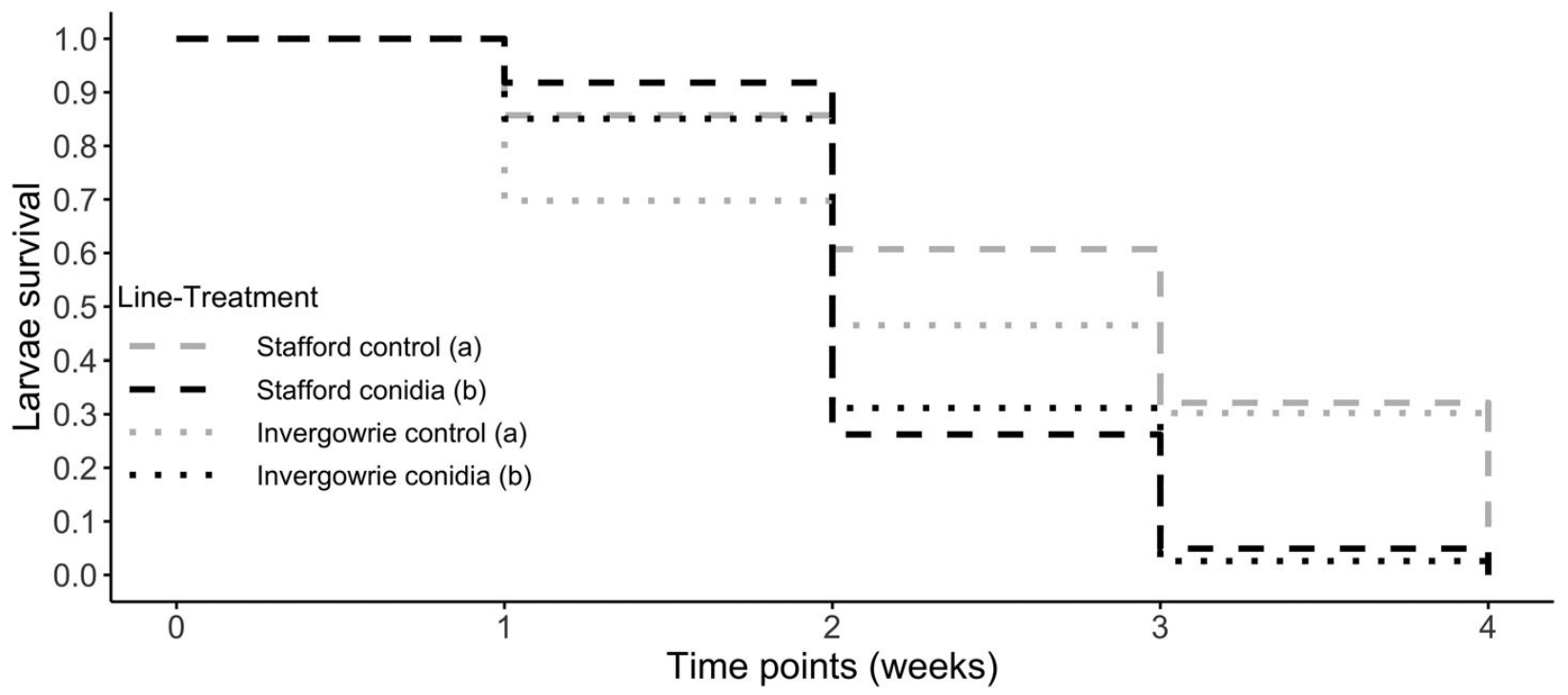

277 Figure 1. Cox regression for survival of vine weevil larvae from two different populations treated

278 with Metarhizium brunneum. Y-axis represents larvae survival while x-axis represents the time 279 points considered for the study (weeks). Line-treatment combinations sharing the same letters 280 were not significantly different (log-rank test: $p$-value $<0.05)$. 
289 Table 1. Probability of survival for larvae from both populations, Stafford and Invergowrie. The 290 table shows the probability of survival as a percentage of the total number of larvae throughout the 291 experimental period given by the Cox regression model. The time points at which mortality was 292 recorded are represented as $1^{\text {st }}$ to $4^{\text {th }}$ week..

293

294

\begin{tabular}{l|llll} 
Probability of survival & $\begin{array}{l}\text { Stafford } \\
\text { control }\end{array}$ & $\begin{array}{l}\text { Stafford } \\
\text { conidia }\end{array}$ & $\begin{array}{l}\text { Invergowrie } \\
\text { control }\end{array}$ & $\begin{array}{l}\text { Invergowrie } \\
\text { conidia }\end{array}$ \\
\hline $1^{\text {st }}$ week & $86 \%$ & $92 \%$ & $70 \%$ & $85 \%$ \\
$2^{\text {nd }}$ week & $61 \%$ & $26 \%$ & $47 \%$ & $31 \%$ \\
$3^{\text {rd }}$ week & $32 \%$ & $5 \%$ & $30 \%$ & $3 \%$ \\
$4^{\text {th }}$ week & $6 \%$ & $0 \%$ & $24 \%$ & $0 \%$
\end{tabular}

